\title{
Prevalence of Sudden and Unexpected Natural Death due to Diseases of Central Nervous System.
}

\author{
Archana Chaudhary ${ }^{1}$, Tulsi Kadel ${ }^{2}$, Harihar Wasti ${ }^{2}$, Pramod Kumar Shrestha ${ }^{2}$ \\ ${ }^{1}$ Department of Forensic Medicine, B \& C Medical College and Teaching Hospital \& \\ Research Center,Birtamode,Jhapa,Nepal \\ ${ }^{2}$ Department of Forensic Medicine, Maharajgunj Medical Campus, Institute of Medicine, \\ Tribhuvan University. \\ Correspondence: \\ Dr Archana Chaudhary Nepal \\ Department of Forensic Medicine, B \& C Medical College and Teaching Hospital \& \\ Research Center,Birtamode,Jhapa,Nepal. \\ Email: archiechaudhary@yahoo.com \\ Phone: +9779801032248
}

Background: The World Health Organization (WHO) has defined sudden unexpected death as a death, non-violent and not otherwise explained, occurring within 24 hours from the onset of symptoms. This study was performed with the objective to evaluate the different neurological causes of sudden and unexpected death.

Methods and materials: this is a cross-sectional analytical study with non-probability consecutive sampling technique over the period of one year. Data were collected, and analyzed using SPSS 20. Data were presented in percentages, and stratifications were used to control the modifiers.

Results: There were total 110 autopsies done during the period of one year for sudden and unexpected deaths, among which $19(17.3 \%)$ were deaths due to neurological causes, where $17(89.5 \%)$ were males and $2(10.5 \%)$ were females. There were $68.43 \%$ deaths seen during cold weather. Smoking, alcohol and drug abuse all seems to have higher prevalence among the sudden death due to neurological cause. Most common causes were subarachnoid hemorrhage (58\%) followed by ganglionic bleed (26\%).

Conclusion: Common cause of sudden death due to neurological disease in our study seem to be due to intracerebral hemorrhage where subarachnoid hemorrhage was more common. The deaths were more common during the cold weather and most of them stopped their heart at emergency department during resuscitation.

Key Words: sudden death, unexpected death, subarachnoid hemorrhage, sudden death in neurological diseases,

$\mathrm{T}$ The World Health Organization (WHO) has defined sudden unexpected death as a death, nonviolent and not otherwise explained, occurring within 24 hours from the onset of

8

Date Submitted: 7/6/2019

Date Accepted: 12/8/2019 symptoms. ${ }^{1}$ The most common cause of these sudden unexpected deaths are coronary artery disease ${ }^{2}$; however, there are a large bunch of cases of such deaths secondary to central nervous system

egneuro Volume 01, Issue 02, 2019

DOI: https://doi.org/10.3126/egn.vli2.25728 
diseases. There are numerous causes of sudden unexpected deaths due to neurological diseases, but most common one are SUDEP ( Sudden Unexpected Death in Epilepsy), ruptured aneurysm, meningitis and so on. 3,4

This study was performed with the objective to evaluate the different neurological causes of sudden and unexpected death in the series of autopsy done at a tertiary center.

\section{Methods and Materials:}

Study design: Cross- sectional analytical study.

Study duration: one year

Sample size: 110 autopsies

Sampling technique: non-probability, consecutive sampling

Study variables: age, sex, location, month of death, smoking, alcohol, drug abuse and cause of death

Analysis was done with software SPSS, Version 20. The mean and standard deviation was calculated for the age. The frequency and percentage were calculated for gender, location, smoking habit, alcohol consumption, drug abuse and cause of death. The effect modifier were controlled through stratification of age, sex, location, smoking habit, alcohol consumption and drug abuse to see the effect of these modifiers on the outcome.

\section{Results:}

There were total 110 autopsies done during the period of one year for sudden and unexpected deaths, among which 19 (17.3\%) were deaths due to neurological causes, where $17(89.5 \%)$ were males and $2(10.5 \%)$ were females. Mean age of presentation was 50.07(SD 16.7) years. Majority of the deaths were seen once the patient had arrived to the emergency department (Table 1), and noticeably, $68.43 \%$ of deaths were seen during cold weather (Table 2). Smoking, alcohol and drug abuse all seems to have higher prevalence among the sudden death due to neurological cause (Table 3).

Table 1: Prevalence of deaths in different locations.

\section{Location}

CNS causes of sudden and unexpected deaths

\begin{tabular}{lc}
\hline Room & $3(15.78 \%)$ \\
Open area & $2(10.52 \%)$ \\
$\begin{array}{l}\text { During transport to } \\
\text { hospital }\end{array}$ & $4(21.05 \%)$ \\
Emergency department & $10(52.63 \%)$ \\
\hline
\end{tabular}

Table 2: Prevalence of death in different parts of the year

\begin{tabular}{ll}
\hline Months & $\begin{array}{l}\text { CNS causes } \\
\text { of sudden } \\
\text { and } \\
\text { unexpected } \\
\text { deaths }\end{array}$ \\
\hline May-Sep (warm weather) & $6(31.57 \%)$ \\
Oct-April (Cold weather) & $13(68.43 \%)$ \\
\hline
\end{tabular}


Table 3: Prevalence of smoking, alcohol, or drug abuse

\begin{tabular}{|c|c|c|}
\hline Variables & & $\begin{array}{l}\text { CNS causes of } \\
\text { sudden and } \\
\text { unexpected } \\
\text { deaths }\end{array}$ \\
\hline \multirow[t]{2}{*}{ Smoking } & No & $6(31.57 \%)$ \\
\hline & Yes & $13(68.43 \%)$ \\
\hline \multirow[t]{2}{*}{ Alcohol } & No & $5(26.31 \%)$ \\
\hline & Yes & $14(73.69 \%)$ \\
\hline \multirow[t]{2}{*}{ Drugabuse } & No & $19(100 \%)$ \\
\hline & Yes & $0(0.0 \%)$ \\
\hline
\end{tabular}

Of these 19 cases, 17 had one or other form of intracranial hemorrhage, in which 11 cases had subarachnoid hemorrhage, 5 had a ganglionic bleed and one had a bleed in the brain stem. Also, there were 2 cases of meningitis (Figure 1)

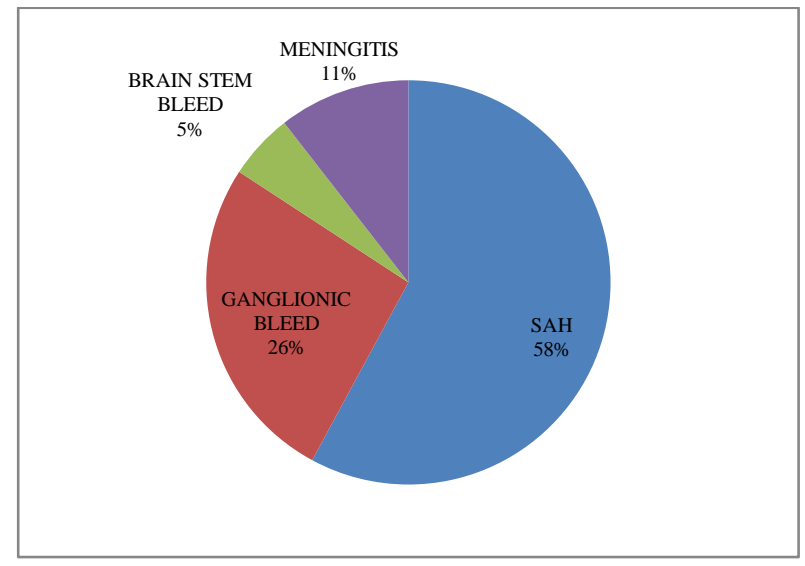

Figure 1: Frequency of the different causes of death due to diseases of the central nervous system

Of all the 11 cases of subarachnoid hemorrhages (Figure 2), two cases were recognized to have multiple aneurysms where one case had aneurysms at the anterior communicating artery, middle cerebral artery and posterior communicating artery and the other had aneurysms at the anterior communicating artery and the basilar tip (Figure 3). In one case, the rupture was of the proximal aneurysm, which was of the posterior communicating artery; and the other had a rupture of the posterior circulation aneurysm, which was a basilar tip aneyrysm.

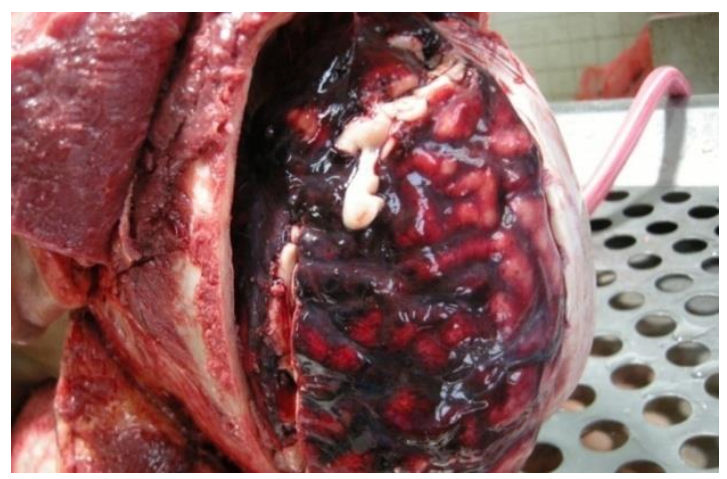

Figure 2: A case of subarachnoid hemorrhage.

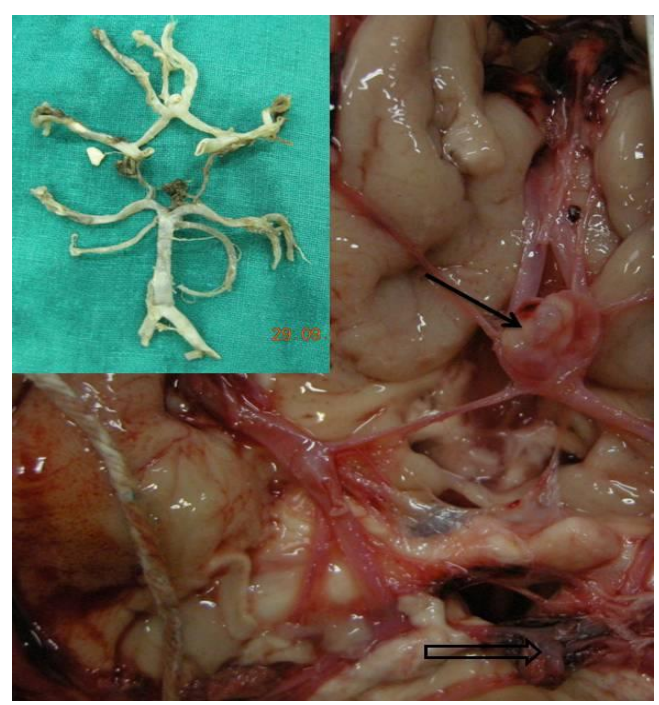

Figure 3: A case with multiple aneurysms, showing anteriorcommunicating artery aneurysm (dark arrow) and a basilar tip aneurysm (open arrow).

egneuro, Volume 01,Issue 02, 2019 
There was also evidence of intraventricular extension of the intracerebral hemorrhage in five cases of subarachnoid hemorrhage and two cases of ganglionic bleed.

The 2 cases of meningitis seemed to have pus deposits throughout the brain (Figure 4).

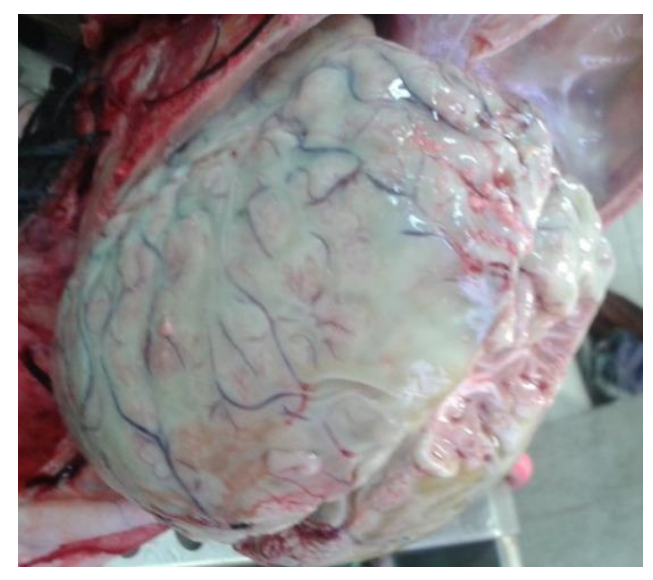

Figure 4: A case of meningitis.

\section{Discussion:}

Hirsch CS et al in their study found that epilepsy was the most common cause of death among deaths due to diseases of the central nervous system. ${ }^{5}$ Similarly, Ficker DM in a study of sudden unexplained death and injury in epilepsy, found that $2-17 \%$ had unexplained death among epileptics. ${ }^{3}$ The diagnosis of the death due to epilepsy is considered to be one of exclusion, and there should always be a detailed history of epilepsy. ${ }^{3,5,6,7}$ However, in this study none of the cases could be considered to be due to epilepsy; rather, one case which had history of epilepsy had a cardiovascular cause of death and hence was excluded from this study.

Although, spontaneous subarachnoid hemorrhage is generally the second most common cause of sudden death among central nervous system diseases, it was the most common cause in our series, with egneuro, Volume 01, 2019
$57.9 \%$ ( 11 of 19 cases) of all the sudden and unexpected deaths due to diseases of the central nervous system. Literatures quotes ruptured berry aneurysm as the most common cause of subarachnoid hemorrhage; $8,9,10$ however, our series had only two such cases and both these had multiple aneurysms with a ruptured posterior communicating artery aneurysm. Blood in the intraventricular system was seen to be rapidly fatal and was present in $17 \%$ of cases of intracerebral hemorrhage in the study conducted by Freytag E in $1966 .{ }^{9}$ In this study, seven out of 17 cases of intracerebral hemorrhage, or $41 \%$, had intraventricular extension of the bleed, where five cases were of subarachnoid hemorrhage and two cases of basal ganglia bleed.

Meningitis is an occasional cause of sudden unexpected death. ${ }^{4}$ Until the late 1980s, most of them were 3 months and 3 years old children, with the organism involved being Hemophilus influenza. At present, acute bacterial meningitis are more common in adults secondary to ear infection and sinusitis, urinary tract infection and pneumonia. The most common organisms now encountered are Streptococcus pneumoniae (40-60 \%), Neisseria meningitis (15-25 \%), Listeria monocytogene (10-15\%) and Haemophilus influenzae $(5-10 \%) .{ }^{4}$ In our study we had not cultured the organism but the gross pattern seems to be of frank bacterial meningitis.

\section{Conclusion:}

Common cause of sudden death due to neurological disease in our study seem to be due to intracerebral hemorrhage where subarachnoid hemorrhage was more common. The deaths were more common during the cold weather and most of them 
stopped their heart at emergency department during resuscitation.

\section{Reference:}

1 International Statistical Classification of Diseases and Related Health Problems 10th Revision (ICD-10) Version for 2010. Ill-defined and unknown causes of mortality. 10 ed: WHO; 2010.

2. Zipes DP, Wellens HJJ. Sudden cardiac death. Circulation. 1998;8(21):2334-51.

3. Ficker DM. Sudden unexplained death and injury in epilepsy. Epilepsia. 2000;41(2):S7-12.

4. Hirschmann JV. Bacterial infections of the central nervous system. In Dale DC and Federman (Eds) Scientific American Medicine. Sci Amer NY 1999:53A.

5. Hirsch CS, Martin DL. Unexpected death in young epileptics. Neurology. 1971;21:682-
6. Nashef L, So EL, Ryvlin P, Tomson T. Unifying the definitions of sudden unexpected death in epilepsy. Epilepsia. 2012;53(2):227-33.

7. Jay GW, Leestma JE. Sudden death in epilepsy. Acta Neurol Scand. 1981;63(82):1-66.

8. Chasson JL, Hindman WM. Berry aneurysms of the circle of Willis. Neurology. 1958;8:41-4.

9. Freytag E. Fatal rupture of intracranial aneurysms. Arch Pathol. 1966;81:41824.

10. Freytag E. Fatal hypertensive intracerebral haematomas. J Neurol Neurosurg Psychiat. 1968;31:616-20. 